\title{
Ascenso y ocaso del Partido Comunista en el movimiento obrero argentino: critica historiográfica y argumentaciones conceptuales
}

\author{
Hernán Camarero
}

UBA-CONICET

Durante el cuarto de siglo que concluyó hacia mediados de la década de 1940, el Partido Comunista (PC) protagonizó una experiencia decisiva en la historia del movimiento obrero argentino. Con la implantación molecular de sus células de empresa y sus agrupaciones gremiales y, más tarde, con la constitución y dirección de los principales sindicatos industriales y de las huelgas fabriles, el PC se convirtió en un impulsor clave de la movilización de los trabajadores. En el transcurso de esos años, el partido logró agrupar a miles de militantes. Asimismo, constituyó múltiples instituciones socioculturales en el seno de la clase obrera: bibliotecas, escuelas, clubes deportivos, agrupaciones femeninas, infantiles y juveniles, asociaciones de inmigrantes, ligas antiimperialistas y antifascistas, entre otras. Esta ascendente presencia politica, social y cultural fue la más alta que el PC consiguió en su historia.

El movimiento que dio vida al comunismo pasó por diversos estadios. Primero, actuó como ala izquierda del Partido Socialista (1912-1917); luego, operó como una organización socialista disidente y revolucionaria de carácter probolchevique (el Partido Socialista Internacional, existente entre 1918 y 1920); finalmente, desde ese último año, ya adoptó el nombre de Partido Comunista, adherente a la Comintern o Internacional Comunista (IC). Todo ese trayecto fue recorrido bajo el liderazgo del tipógrafo José F. Penelón y, más tarde, de la dupla conformada por Victorio Codovilla y Rodolfo Ghioldi. El PSI-PC se presentó como expresión de los nuevos tiempos abiertos por la Revolución de Octubre en Rusia y el ascenso revolucionario europeo de postguerra. No obstante, en su primera etapa, esta corriente fue una expresión marginal en el movimiento obrero. Fue desde mediados de los años 20 cuando su gravitación se fue haciendo cada vez más marcada en el mundo de los trabajadores, al tiempo que intentó diseñar una base programática local para su accionar. Sin poder escapar de las tendencias generales del proceso mundial, el partido fue consustanciándose con los intereses 
de la naciente burocracia soviética y asumiendo todos los presupuestos teóricos, políticos y organizativos del estalinismo.

Treinta años después de su aparición más embrionaria, cuando el $\mathrm{PC}$ estaba alcanzando su máxima incidencia, dirigiendo la mayoría de los gremios industriales y adquiriendo una fuerza indiscutible en la conducción de la Confederación General del Trabajo (CGT), se produjo una serie de acontecimientos que trastocaron esta evolución histórica e introdujeron un giro inesperado. A partir del golpe militar de junio de 1943 y el sólido vínculo que empezó a unir al coronel Juan D. Perón con los asalariados, esta empresa política de izquierda acabó naufragando con bastante rapidez. Sobrevino el eclipse y la progresiva evaporación de la influencia comunista entre los trabajadores. En definitiva, la llegada del peronismo operó como un punto de inflexión inevitable en la historia de las izquierdas en la Argentina.

En este artículo ensayamos algunas reflexiones analíticas que permitan explicar este proceso de ascenso y ocaso del comunismo en el movimiento obrero, sintetizando, complementando y redefiniendo algunas de nuestras anteriores incursiones (Camarero, 2007 y 2008). Ellas están basadas en un exhaustivo relevamiento de las fuentes primarias disponibles, sobre todo a partir de nuevos archivos (como los provenientes de la ex URSS), que incluyen miles de materiales públicos e internos, antes inhallables o inexplorados. En particular, buscamos indagar aquí: las condiciones sociales que hicieron posible aquel proceso; los rasgos específicos del comunismo como corriente del movimiento obrero; la manera en que incidieron las distintas formas de organización e intervención militante, las tácticas políticas y las estrategias globales adoptadas por el partido; y, por último, el modo como afectó la irrupción del peronismo en 1943-1945. Apostamos al criterio que nos parece más adecuado para abordar la historia de la izquierda y el movimiento obrero: determinar cómo ambos coadyuvaron en sus propias constituciones sociales, politicas, ideológicas y culturales. Este enfoque, que introduce el análisis clasista en el estudio de las estructuras políticas y la dimensión subjetiva y politica en el examen de la clase, por otra parte, es el más fértil para estudiar las características y evolución de un partido. ${ }^{1}$

El procedimiento más apropiado para exponer nuestras argumentaciones y distinguir su originalidad requiere de una pregunta inicial: ¿De qué modo fue estudiada la experiencia comunista en el mundo de

1. Al fin y al cabo, como sostenía Gramsci, la historia de un partido "no podrá ser menos que la historia de un determinado grupo social" y, por ello, "escribir la historia de un partido no significa otra cosa que escribir la historia general de un país desde un punto de vista monográfico, para subrayar un aspecto característico" (1984: 30-31). 
los trabajadores entre las décadas de 1910 y 1940? La respuesta no sólo permite identificar los ejes esenciales que se dirimen en torno al tema, sino que también puede operar como un camino para problematizar algunos de los avatares en el desarrollo de la historiografia sobre el movimiento obrero y la izquierda en la Argentina. Para encarar esta labor, en el siguiente apartado organizamos un recorrido de la producción bibliográfica, que encaró el tema, en la mayoría de los casos de manera indirecta o parcial. $^{2}$

\section{Comunismo y movimiento obrero: una revisión historiográfica}

La primera estación de nuestro itinerario nos conduce a la "historia oficial" partidaria. Sus límites son bien evidentes: ella estuvo definida por una tónica propagandística, arribando a ciertos niveles de malversación de la verdad histórica, comunes en el estalinismo. Están los relatos esencialmente internos e "institucionales", centrados en la descripción de las posiciones del PC y en sus vicisitudes como aparato político, cuya expresión paradigmática es Esbozo de Historia del Partido Comunista de la Argentina (1947). ${ }^{3}$ Por otra parte, tenemos a Origen y desarrollo del movimiento sindical argentino (1958), de Rubens Iscaro, primera obra en considerar en forma sistemática la presencia del PC en el ámbito gremial, que pertenece a la tradición de las grandes "historias militantes" del movimiento obrero. Por último, las biografias y autobiografias de los principales cuadros obreros comunistas, que recrean experiencias individuales y colectivas en conflictos y gremios clave, como el metalúrgico, el de la carne, el de la construcción, el del calzado, el del vestido y el ferroviario. Crónicas proletarias, de José Peter (1968), fue el texto arquetípico de esta literatura, continuada por Jesús Manzanelli, Pedro Chiarante y Miguel Contreras, entre muchos otros. En conjunto, todos estos textos proveyeron de información básica, pero con un criterio de selección/manipulación de las fuentes y en varios casos de tergiversación de los hechos, que sólo buscaron la justificación de las políticas sustentadas por la dirección partidaria. ${ }^{4}$ Ahora bien, estas obras brindaron

2. Para un análisis integral sobre la historiografia del comunismo argentino: Campione (1996); Cernadas, Pittaluga y Tarcus (1998); Camarero (2001 y 2005).

3. En las décadas siguientes, este texto fue continuado por varios otros que casi repitieron los mismos argumentos y aportaron sólo algunos datos nuevos: Paso (1983); Arévalo (1983); Fava (1983).

4. Georges Haupt señalaba, respecto de esta narrativa de los partidos comunistas, que se trataba de "una historia utilitaria, proyectiva, que acaba convirtiéndose en 
elementos para intentar demostrar una idea central: hasta 1945 el PC constituía una fuerza política que había alcanzado cierta influencia de masas en la clase trabajadora. Este diagnóstico no carecía de elementos de aproximación a la realidad histórica. Sin embargo, la tosquedad de la mayor parte de esta narrativa, su carácter falsario y autoproclamatorio y las propias vicisitudes del partido (y de la izquierda toda) tras la irrupción del peronismo fueron desacreditando aquella convicción y alienándola del sentido común historiográfico-político.

Esto fue favorecido con la difusión adquirida, desde los años 50 y 60, por las historias de cuño nacional-populista de izquierda y de izquierda nacional. Las obras de Rodolfo Puiggrós (1956) y Jorge Abelardo Ramos (1962), fueron las paradigmáticas. A partir de una pobrísima infraestructura documental, estos ensayos argumentaron que la presencia comunista (y en buena medida de toda la izquierda) en el proletariado de entreguerras fue insignificante o politicamente improductiva, debido a la impronta "antinacional" y "extranjerizante" de ese partido, que habria comprendido y representado mejor al inmigrante y al pequeño burgués que a los trabajadores nativos. Al "vicio de origen" del comunismo se habrian agregado los errores de sus orientaciones estratégicas: primero, la linea ultraizquierdista y sectaria de "clase contra clase", y luego la del "frente popular", que lo habrian colocado en posiciones contrapuestas a las del campo nacional-popular. Para Ramos, los yerros del PC local se debían a su rol de mera encarnación de los intereses de la burocracia soviética, lo cual hizo que las equivocadas directivas estalinistas fueran reproducidas sin contradicciones; para Puiggrós, en cambio, estos fracasos provenían de la incomprensión que el PC tenía con respecto a las posiciones de la IC. La "traición a los trabajadores" habría provocado el repudio de éstos al comunismo, dejándolos en un vacío de representación que, luego, con toda legitimidad, llenaría el peronismo. Si bien Ramos-Puiggrós advirtieron la línea de capitulación del estalinismo a uno de los bandos en los que la burguesía argentina dirimió sus disputas en los años 40, lo hicieron para justificar su propia capitulación histórico-política al otro bando patronal, el liderado por Perón (así como antes, cuando denunciaban el sectarismo comunista, embellecian al yrigoyenismo). También resulta un desafio al orden mismo de la lógica la visión sobre un partido que desertaba de su papel de dirección certera de la clase obrera, cuando al mismo tiempo se le negaba (y a cualquier tipo de izquierda socialista o anticapitalista) una presencia sustancial en el seno de dicha clase. En definitiva, las explicaciones del

una historia manipuladora". (Haupt, 1986: 17). Sobre el carácter de la historia oficial comunista en el mundo: Anderson (1984); Groppo y Pudal (2000: 19-25). 
nacional-populismo de izquierda cayeron en la impotencia argumentativa. Durante medio siglo más, esta corriente tendió a exhumar el mismo repertorio interpretativo (ver: Galasso, 2007).

$\mathrm{Si}$ el vínculo entre movimiento obrero y comunismo quedaba mal comprendido en las visiones ensayísticas antes expuestas, el despliegue de ciertos estudios de la sociología de la modernización en el ámbito académico, como los impulsados por Gino Germani (1962), contribuyó a reafirmar este diagnóstico. Aunque los planteos de éste carecian de toda empatía con el fenómeno peronista y se hallaban muy distantes del nacional-populismo de izquierda, en un aspecto, involuntariamente, ambos acabaron empalmando. Germani presentó a la Argentina industrial emergente en los años 20 y 30 desde el prisma de un corte abrupto entre una "vieja" y una "nueva" clase obrera, en donde la primera, en su mayoría descendiente de la inmigración europea, aparecía naturalmente inclinada a ideologías de clase, portaba un carácter autónomo y poseía una extensa experiencia industrial, urbana, política y sindical, mientras la segunda, reclutada en la migración interna desde las provincias rurales, se mostraba heterónoma y privada de aquella experiencia de clase. Por estas razones, encontraba que estos nuevos contingentes laborales habrian sido esquivos a los partidos de clase, como el PC y el PS, y se habrian convertido en masa en disponibilidad para el ejercicio del proyecto autoritario encarnado por Perón desde 1943. De este modo, también se arribaba a la misma conclusión, a saber, que partidos como el PC se habrian mostrado incapaces para organizar a los componentes crecientemente mayoritarios en el mundo del trabajo. En suma, sea porque el liderazgo de Perón surgía sobre un vacío de representación o porque desplegaba sus artes demagógicas sobre una masa en disponibilidad, el avance comunista en los nuevos y viejos integrantes del movimiento obrero desde los años treinta era expulsado de la historia.

Una destacada y creciente elaboración hecha en el espacio académico, en un cruce disciplinario entre historia y sociología histórica, aún en clave marxista, produjo, ya desde fines de la década del 60 y a lo largo de los años 70, una serie de aportes sobre el movimiento obrero del período de entreguerras y, en especial, del preperonismo. Ellos sirvieron para comenzar a echar luz sobre la experiencia laboral del comunismo, sorteando algunas de las incapacidades e incomprensiones arriba apuntadas. Pueden referenciarse, en un primer ciclo, las obras de Celia Durruty (1969) y Miguel Murmis-Juan Carlos Portantiero (1971), luego, las de Hugo del Campo (1983) y Juan Carlos Torre (1990). Pudieron erosionar los contornos de la supuesta antinomia entre vieja y nueva clase obrera, al destacar la existencia de fuertes interrelaciones entre esos dos sectores, que Germani oponia con tanto énfasis, mostrando 
que ni el peronismo fue extraño al universo de la vieja guardia sindical ni la izquierda fue antitética a los nuevos componentes del proletariado fabril. Fue en este último sentido que aportaron a un redescubrimiento/constatación de la fuerte implantación obrera del PC en los años 30 y 40, aunque sin examinar en profundidad sus causas ni las razones que explicarian el ocaso de ésta. Especial relevancia tuvo el breve pero pionero trabajo de Durruty consagrado al auge de la Federación Obrera Nacional de la Construcción (FONC), en donde ya se sugeria la contribución comunista al desarrollo de un "sindicalismo moderno" desde aquella época.

Generacional, ideológica y políticamente vinculado a varios de estos autores, a partir de la experiencia de la revista-grupo Pasado y Presente, José Aricó (1979) incursionó de manera específica en la temática, con un breve ensayo proyectivo, diseñando algunas hipótesis que permitiesen entender tanto la creciente inserción comunista en el movimiento obrero que él ubicaba desde los años treinta como su posterior erosión. Fue el primero en jerarquizar en el análisis, de una manera menos mecánica que en otros abordajes, el impacto que tuvieron las diferentes estrategias políticas del PC. Para explicar la expansión comunista en la clase obrera, Aricó llamó la atención sobre la adopción de la línea de "clase contra clase", una concepción sectaria que tuvo la paradójica utilidad de fomentar la proletarización del partido, pues lo dirigió hacia una conquista acelerada de las masas obreras. Según Aricó, la siguiente orientación general del PC, la del "frente popular", lo llevó a tomar distancia de las reivindicaciones obreras mínimas en aras de un deseable acuerdo con sectores de la burguesía dispuestos a formar un bloque aliado antifascista; alli se habrian demostrado los límites de la penetración comunista, pues resultó evidente que el PC no logró convencer a la mayoría de los trabajadores de las ventajas de tal política. Su influencia sindical no pudo traducirla a un nivel político-ideológico y alcanzar así una auténtica posición hegemónica entre los trabajadores (aunque hasta 1943 parecia la corriente en mejores condiciones de lograr tal objetivo). El defecto del análisis de Aricó es que ponía todo el peso explicativo del eclipse comunista en las causas endógenas (las apuestas estratégicas del estalinismo), sin sopesar el contexto general y el papel de las otras estrategias puestas en juego, en particular la del emergente sector "nacional-populista" de la burguesía, con sus políticas de represión, cooptación e integración del movimiento obrero.

Durante las últimas décadas se agregaron otros estudios que consideraron globalmente al movimiento obrero en el preperonismo, en los cuales se hizo frecuente el señalamiento de la presencia comunista, aunque sin identificar el proceso de su implantación originaria (entre otros: Matsushita, 1983; Tamarin, 1985; Godio, 1989). Si bien logra- 
ron ampliar el conocimiento sobre el vínculo entre la izquierda y los trabajadores, sólo tendieron a iluminar esta relación en las instancias directivas del sindicalismo, sobre todo, en la CGT, concentrándose en la descripción de las tácticas generales de las distintas corrientes y en las disputas entre ellas. No analizaron al PC en cada gremio (una excepción en este sentido fue la obra de Torcuato S. Di Tella, 2003) ni en el tipo de lazo que se estableció entre el partido y los sindicatos, las concepciones que animaron a esa ligazón y los recursos organizacionales puestos en juego. Roberto Korzeniewicz (1993) y Joel Horowitz (2004), asimismo, examinaron cómo la reactivación de la conflictividad industrial desde mediados de los años 30 brindó una oportunidad al PC para constituir sindicatos únicos por rama. La actuación comunista en el movimiento obrero quedó registrada en otros documentados trabajos sobre las luchas obreras de los años 30, en especial, las huelgas de la construcción y general de 1935-1936 (Iñigo Carrera, 2000, entre otros). Alli la relación entre el PC y la clase obrera queda calibrada parcialmente, pues el papel del primero aparece subordinado y no explorado en su especificidad, al pretender comprenderlo exclusivamente a partir de las estrategias objetivas que poseería la propia clase obrera.

Hubo otros aspectos del tema, antes desatendidos, sobre los cuales se ha avanzado en los años más recientes. Uno de ellos es el del examen de las intervenciones del PC en el sitio de trabajo, que habilita una indagación acerca de las prácticas concretas de la militancia obrera. En esta dimensión, pueden ubicarse desde algunos estudios de caso que hicieron alusión específica al comunismo (como el de Mirta Lobato, 2001, referido a los trabajadores de los frigoríficos de Berisso) o las investigaciones sobre la actividad obrera de base (Ceruso, 2010). El otro campo es el de los análisis de casos regionales, que extendieron la constatación de la influencia comunista en el mundo del trabajo fuera de Buenos Aires, en ciudades y provincias como Rosario, Mar del Plata, Tucumán y Córdoba (Águila, 1991-1992; Pastoriza, 2005; Fernández de Ullivarri, 2010; Mastrángelo, 2011). Finalmente, señalemos que la gran mayoría de los textos académicos, ensayísticos o periodísticos en los últimos tiempos dedicados específicamente al comunismo como partido (una producción muy heterogénea en cuanto a su valor y nivel de profundidad), repasaron las distintas estrategias y tácticas adoptadas en esos años y su impacto en la política nacional, las relaciones con la IC, y los debates internos, las rupturas y las crisis de la organización, aunque prestaron escasa atención a sus lazos con el mundo del trabajo.

El balance que arroja este recorrido historiográfico indica que, al menos, hasta hace poco más de una década, la experiencia de los comunistas entre los trabajadores hasta la aparición del peronismo continuaba inexplorada o con un tratamiento superficial, en base a una reducida 
consulta de fuentes primarias. No existía una reconstrucción general y precisa, ni argumentaciones consistentes, para explicar el proceso de inserción y posterior desplazamiento del PC en el movimiento obrero, ni el genuino impacto que tuvo la aplicación de las diferentes estrategias cominternistas, ni los escenarios sociales y las disposiciones que posibilitaron aquella experiencia de auge y declive en comparación con las otras corrientes actuantes (anarquistas, socialistas y sindicalistas). En nuestras investigaciones hemos intentado responder a estos desafios planteados (entre otras, Camarero, 2007 y 2008), con una serie de hipótesis y resultados, a los cuales deben sumarse los aportes más recientes de otros autores arriba mencionados.

A continuación, encaramos un ejercicio de problematización sólo de algunas de las conclusiones alcanzadas, en pos de contribuir a un ensayo interpretativo global sobre esta materia, cuya ausencia constituía una de las tantas falencias presentes en la historiografia sobre el movimiento obrero y la izquierda en la Argentina. Nos limitaremos a señalar de manera necesariamente concisa algunos grandes núcleos temáticos, complementando y/o contraponiendo con nuestros enunciados lo que entendemos que significan los vacíos, equívocos o ambigüedades más comunes del sentido común historiográfico. La pretensión es abrir ciertas discusiones y situar campos de polémica con certezas establecidas.

\section{Condiciones sociales y modalidades de intervención del PC en el proletariado industrial}

¿Cuál fue el contexto histórico-sociológico que hizo crecientemente eficaz la empresa comunista entre los trabajadores durante el periodo de entreguerras? En aquella época, como producto de la industrialización sustitutiva, se verificó una presencia cada vez más gravitante de obreros en los centros urbanos (especialmente, la Capital Federal y el conurbano bonaerense), con un gran monto de reivindicaciones insatisfechas, pues las tendencias al aumento del poder adquisitivo del salario y al descenso de los índices de desocupación de la segunda mitad de los años veinte, se revirtieron tras la crisis de 1930, y los índices sólo volvieron a mejorar, desde mediados de esa década, exclusivamente en lo que hace a la baja del desempleo. Fueron años de intensa acumulación del capital, con incremento de la explotación laboral y escasas iniciativas redistributivas. Esta industrialización impuso cambios en las orientaciones del movimiento obrero, con inserción débil en estos nuevos sectores laborales.

Hubo una situación objetiva sobre la cual la historiografia no ha prestado debida atención. El crecimiento de un proletariado industrial nuevo, numeroso y concentrado (por ejemplo, en el rubro de la 
construcción, de la carne, de la metalurgia, de la madera, del vestido y textil), mayoritariamente semicalificado o sin calificación, en donde la situación laboral era ostensiblemente más precaria, dejaba un vacío de representación. En particular, las tareas de organización de los obreros en estos espacios se presentaban plagadas de dificultades, originadas en la hostilidad de los empresarios y del Estado. Esos trabajadores se enfrentaban a formidables escollos para agremiarse y hacer avanzar sus demandas en territorios poco explorados por la militancia. Para abrirse paso a través de esos obstáculos, se requerian cualidades políticas que no todas las corrientes del movimiento obrero estaban en posibilidad de exhibir. Allí habia disponibilidad y oportunidad para el despliegue de una específica acción sindical y política. En este escenario, estaba casi todo por hacer y los comunistas demostraron mayor iniciativa, habilidad y capacidad para acometer los desafios, sobre todo si realizamos una comparación con los anarquistas, socialistas y sindicalistas. Usando una imagen metafórica: el PC se concebía a sí mismo capaz de abrir senderos o "picadas" en una selva, es decir, apto para habilitar caminos no pavimentados y alternativos a los reconocidos.

Independientemente de las estrategias generales que el PC impulsó en el marco de su progresiva conversión al estalinismo (desde la ultraizquierdista linea de "clase contra clase" hasta la conciliadora y reformista politica del "frente popular"), y que, en definitiva, lo incapacitaron para convertirse en una alternativa de dirección revolucionaria de la clase obrera argentina, lo cierto es que, en los hechos, dicho partido no dejó de ser la principal corriente en promover prácticas combativas y clasistas en el ámbito industrial. Los comunistas recrearon parcialmente una experiencia confrontacionista como la que anteriormente había sostenido un anarquismo que ahora se mostraba cada vez más exangüe. Las corrientes ácratas habian logrado un fuerte ascendiente en el periodo embrionario del movimiento obrero, en el que muchos de sus integrantes todavía resistian a la lógica del trabajo industrial y pugnaban por encontrar márgenes de libertad. A partir de los años 20, esa situación varió: el disciplinamiento se hizo inapelable en una sociedad urbana en creciente industrialización, en la que comenzaban a imponerse nuevas formas de explotación que, merced a cambios tecnológicos y un mercado de trabajo cada vez más competitivo, cercenaban la autonomía a los obreros y liquidaban los oficios artesanales. Estaba surgiendo una clase obrera moderna, carente aún de una legislación laboral sistemática. Los incentivos estaban dados para la generalización de un más maduro sindicalismo industrial por rama. La negativa de la FORA V Congreso a aceptar esta realidad y a reconvertirse en esa dirección, para preferir, en cambio, seguir como entidad federativa de sociedades de resistencia y gremios por oficio anarquistas, fue condenando a esa corriente a la 
irrelevancia. Cuando, desde el espacio libertario, surgieron proyectos que intentaron remediar ese déficit, por ejemplo, los de la Federación Anarco Comunista Argentina y el grupo Spartacus, ya era tarde: el PC había ganado las posiciones centrales en el sindicalismo industrial, desde una posición claramente obrerista.

En otra importante sección del universo laboral, en cambio, la penetración comunista fue mucho más limitada. Entre los asalariados del transporte, los servicios y algunos pocos manufactureros tradicionalmente organizados, con muchos trabajadores calificados (maritimos, ferroviarios, tranviarios, municipales, empleados de comercio y del Estado, telefónicos y gráficos, entre otros), la hegemonía era disputada por socialistas y sindicalistas, tendencias que desde mucho tiempo atrás venían negociando con los poderes públicos y ya habian obtenido (o estaban en vísperas de hacerlo) conquistas efectivas para los trabajadores. Los sindicalistas confiaban en sus acercamientos directos con el Estado; los socialistas apostaban a potenciar su fuerza con su bancada parlamentaria, desde la cual apoyaron los reclamos laborales, en especial los provenientes de sus gremios afines. En ambos casos, se privilegiaba la administración de organizaciones existentes, que gozaban de poder de presión y estaban en proceso de complejización e institucionalización, más aún, en varios casos, de burocratización. En el caso de los ferroviarios, incluso, ya habian dado lugar al surgimiento de una suerte de elite obrera. En suma, aquellos eran territorios ocupados y relativamente adversos, en donde los comunistas no encontraron oportunidades para incidir de modo preponderante.

Si las condiciones parecian propicias para el despliegue de una experiencia clasista de organización y movilización en el ámbito obrero fabril, cabe examinar cuáles fueron las técnicas de implantación, las formas de trabajo y las modalidades de intervención de los comunistas en dicho espacio, que les otorgaron ventajas decisivas para afrontar esta labor hasta comienzos de la década de 1940. Esto exige recordar una precisión respecto a la temporalidad histórica que antes habíamos señalado. En el período formativo de esta corriente, entre 1912 y 1925 (como fracción de izquierda del socialismo, como partido socialista revolucionario, $\mathrm{y}$, por último, como partido comunista durante su primer lustro), la posición ocupada por ella en el mundo del trabajo fue marginal. Se trataba de un partido que había logrado establecer ciertos vínculos con el mundo proletario, pero de un modo asistemático y poco profundo, sin presencia orgánica en los sitios de trabajo, con escasa incidencia en las estructuras sindicales y sin mucha experiencia en la dirección de los conflictos y organismos nacionales del movimiento obrero.

¿Cuándo fue que la inserción obrera de los comunistas conoció un salto cuantitativo y cualitativo? La pregunta es clave y no había sido 
abordada en ningún estudio histórico. Nuestra hipótesis es que ello ocurrió desde 1925, cuando el PC adoptó la orientación de la "proletarización" y la "bolchevización". Esto significó un cambio en su estructura: la reubicación de todos los militantes en clandestinas células obreras (sobre todo, las de "empresa o taller"), que significaron una novedosa forma de organización de base antipatronal. Ellas pasaron a ser la entidad fundamental de un partido que viró hacia una actividad combativa y eminentemente ilegal. Al mismo tiempo, esta última se fue haciendo más jerárquica, centralizada y monolítica, en sintonía con los postulados de una Comintern que iniciaba su proceso de burocratización. Lo cierto es que, a diferencia de la década anterior, desde ese entonces y hasta 1943, el PC mutó en una formación política integrada mayoritariamente por obreros industriales, que buscó poseer y conservar ese carácter. Si el comunismo devino en una corriente especialmente apta para insertarse en este proletariado, fue porque se mostró como un actor muy bien dotado en decisión, escala de valores y repertorios organizacionales. Los comunistas contaron con recursos infrecuentes: un firme compromiso y un temple único para la intervención en la lucha social y una ideología redentora y finalista (una peculiar manera de concebir al "marxismoleninismo"), que podía pertrecharlos con sólidas certezas doctrinales. Al mismo tiempo, las células y otros organismos de base, así como los grandes sindicatos únicos por rama, resultaron muy aptos para la penetración en los ámbitos fabriles y para el agrupamiento de los obreros de dicho sector. En no pocos territorios industriales, los comunistas actuaron sobre tierra casi yerma y se convirtieron en la única voz que convocaba a los trabajadores a la lucha por sus reivindicaciones; en otros, debieron dirimir fuerzas con distintas tendencias. En ambos casos, la implantación fue posible gracias a esa estructura partidaria celular y blindada, verdadera máquina de reclutamiento, acción y organización, que el PC pudo instalar en una parte del universo laboral.

Las organizaciones sindicales dirigidas o influenciadas por el PC desplegaron una linea combativa y confrontacionista, la cual se expresó en violentos conflictos durante el segundo gobierno de Yrigoyen, la dictadura uriburista y las presidencias de Justo, Ortiz y Castillo. Sólo para ejemplificar esto, apuntemos la seguidilla de duras y estridentes huelgas: la de la localidad cordobesa de San Francisco, de 1929; las del ramo de la madera, en 1929, 1930, 1934 y 1935; las de los frigoríficos, desde 1932 en adelante; la de los petroleros de Comodoro Rivadavia, ese mismo año; la masiva y extraordinaria de los trabajadores de la construcción de 1935-1936 (combinada con huelga general); y la innumerable cantidad de paros entre los metalúrgicos, textiles y del vestido, entre otros, que el PC impulsó en los años siguientes. El costo de esa resistencia no fue menor: el PC sufrió una sistemática persecución por 
parte de la Sección Especial de Represión del Comunismo y cientos de sus adeptos fueron encarcelados, deportados (merced a la aplicación de la Ley de Residencia) y/o sufrieron sistemáticas torturas, entre ellos, buena parte de los miembros del Comité Central. El partido no sólo fue declarado ilegal sino que hubo un proyecto en el Senado de la Nación para convertir esa persecución en ley.

\section{Aportes y legados del comunismo al desarrollo de un nuevo sindicalismo de masas}

Existe una cuestión que fue apenas encarada por la historiografia referida al movimiento sindical de entreguerras y es la del legado y el aporte específico que el PC dejó a este último. Ello debe indagarse, sobre todo, a partir del período que se abre desde mediados de la década de 1930, cuando el partido completó su implantación, logró el control de importantes organizaciones gremiales y encontró un lugar en la conducción de la CGT (consiguiendo una destacada cantidad de cargos en el Comité Central Confederal de dicha entidad y, en 1942, su vicepresidencia, en manos del albañil Pedro Chiarante). El PC impuso a sus cuadros como secretarios generales de los seis sindicatos clave del sector industrial: la poderosa Federación Obrera Nacional de la Construcción (FONC), la Federación Obrera de la Industria de la Carne (y su extensión, la Federación Obrera de la Alimentación), el Sindicato Obrero de la Industria Metalúrgica, la Unión Obrera Textil, la Federación Obrera del Vestido y, posteriormente, el Sindicato Único de Obreros de la Madera. La gran mayoría de ellos eran miembros del propio Comité Central del PC en 1943, una situación que históricamente no se había dado ni se volvería a repetir en otro partido de la izquierda argentina. Esas y otras organizaciones sindicales dirigidas por el PC superaban los cien mil afiliados/cotizantes hacia principios de los años 40 .

Los militantes del PC generalizaron (y en algunos casos, introdujeron) una serie de características novedosas en el sindicalismo único por rama industrial. Una de ellas fue la creación y expansión de los Comités de Empresa y las Comisiones Internas de fábrica, que irradiaron los tentáculos del gremio hasta los sitios de trabajo y canalizaron las demandas a través de una instancia de movilización y organización de base (Ceruso, 2010, ha profundizando muy bien en este aspecto). Otra fue el creciente pragmatismo y flexibilidad táctica que comenzó a postular el partido con respecto a la negociación con el Estado, en particular, con un Departamento Nacional del Trabajo (DNT) que expandía su voluntad intervencionista. Al mismo tiempo, los comunistas se orientaron hacia un tipo de sindicato que situaba su horizonte en la conformación de una "organización de masas" y en su fortalecimiento sobre "sólidas 
bases orgánicas". Se pretendía un sindicato más "moderno", en el que se combinaran diversas funciones, tanto las referidas a las de la lucha reivindicativa (mejores salarios y condiciones laborales, indemnizaciones por despido, vacaciones pagas, entre otras), como las del mutualismo, la salud, la educación y la recreación. Como parte de estas nuevas misiones, estuvo la negociación de cada vez más ambiciosos convenios colectivos con las entidades patronales, a partir de comisiones paritarias reguladas bajo el marco del DNT.

Este proceso descripto implicó la mayor institucionalización y centralización de las estructuras gremiales, un fenómeno que condujo al intento de crear los sindicatos únicos por rama a nivel regional, los cuales debian aparecer subordinados a la federación nacional de industria. Se trataba de un esquema con estructuras de primero y segundo grado, que alcanzó a plasmarse con claridad en la FONC, arquetipo del nuevo modelo de organización propuesto por los comunistas. Esta armazón más compleja, polifuncional y pragmática se trazó, por otra parte, objetivos alejados de los tradicionales tópicos de la acción directa, que prefiguraban principios ideológicos afines a cierto colaboracionismo de clases: buscaban "liquidar la anarquía existente en la industria", "disminuir la posibilidad de conflictos", "fomentar la industria nacional" y "garantizar y expandir la legislación obrera". Asimismo, si bien en este período sería dificultoso sostener la existencia de un genuina burocracia sindical dentro de esta estructura montada por los comunistas, como así tampoco en la vinculada a socialistas y sindicalistas (entre otras cuestiones, porque entendemos que el fenómeno de plena coagulación de la burocracia como capa se verificó con la irrupción del estatismo burgués peronista), es indudable que ciertos fenómenos de burocratización estaban despuntado en estos espacios.

Sería equívoco ubicar a este naciente y "sofisticado" sindicalismo de masas como algo inédito. En buena medida, este modelo, articulador de nuevos objetivos, prácticas e instituciones, estaba germinando en el movimiento obrero desde antes que los comunistas se hicieran fuertes en la dirección sindical. Pero estaba casi limitado al sector transporte y servicios. Los militantes del PC se sirvieron del mismo, lo adoptaron y lo extendieron en el área de la producción manufacturera y de la construcción. Así, generalizando experiencias y concepciones que luego fueron desarrolladas a un mayor nivel y potenciadas por el Estado peronista, que a su vez introdujo elementos novedosos, se fue completando el definitivo pasaje de un sindicalismo de minorias a otro de masas. ${ }^{5}$ Las conclusiones en este punto son evidentes: todo análisis del surgi-

5. Un estudio clásico que analizó en el movimiento obrero francés el pasaje del "sindicalismo de minorias" (impulsado por obreros calificados, orgullosos de su artesanía, 
miento del sindicalismo industrial maduro en la Argentina, esbozado en sus trazos gruesos en la década anterior al triunfo peronista, debe contemplar prioritariamente la intervención del comunismo, el actor político que orientó esta etapa inicial en el ámbito fabril. A los factores de ruptura que aportó el peronismo, hay que agregar estos elementos de continuidad con experiencias previas.

\section{El impacto de las variaciones de la estrategia cominternista: de "clase contra clase" al "frente popular"}

Un asunto a esclarecer es el de la influencia que tuvo la cambiante estrategia de la Comintern en cuanto a la eficacia de la inserción del PC en el movimiento obrero, más allá del debate acerca de si las líneas eran "correctas" o no desde un punto de vista político. Debe partirse de una constatación, que no ha sido claramente advertida en la historiografia: la presencia del comunismo entre los trabajadores progresó mientras la organización actuó bajo diversos lineamientos, sucesivamente: los del "frente único" (1921-1928), los de "clase contra clase" (1928-1935) y los del "frente popular" (1935 en adelante). Es decir, ella siguió una curva de ascenso más o menos constante, que parece independizarse de estos virajes y, en parte, de las variaciones del contexto socioeconómico y político del país. No puede hacerse abstracción de estos elementos, pero tampoco resultaria acertado negar que para comprender la implantación laboral del PC debe prestarse suma atención a las relativas autonomía y continuidad de sus prácticas de intervención militante y a los rasgos antes analizados de su cultura politica obrerista. Las estrategias se modificaron e impusieron nuevas caracterizaciones políticas, pero sus militantes continuaron desarrollando una serie de rutinas de movilización y organización de la clase trabajadora que permanecieron más o menos inalterables. Aunque, en última instancia, el peso de aquellas estrategias operó como factor decisivo, y sus alteraciones no fueron inocuas para explicar los avances y retrocesos de la influencia obrera del comunismo. Por lo tanto, ellas deben ser examinadas con cuidado.

Es inexacto el señalamiento de Aricó (1979), del cual se abastecieron ciertas periodizaciones sobre el nivel de presencia de la izquierda en el movimiento obrero, cuando sostiene que el inicio de cierta conquista de las masas por el PC se produjo hacia principios de los años 30 ,

y basado en organizaciones descentralizadas y apolíticas) al "sindicalismo de masas", es el de Collinet (1955). Lo que en la Argentina se identificó como propio del período peronista, aquél ya lo veía como característico de la era de dominio comunista sobre el movimiento obrero. 
momento a partir del cual habrian comenzado a cosecharse los frutos de la política sectaria pero al mismo tiempo muy combativa de "clase contra clase" (propia del llamado "tercer periodo" de la IC). Creemos haber demostrado que esta penetración fue previa al establecimiento de dicha estrategia, pues se inició hacia 1925, y, al mismo tiempo, que los resultados de aquella no fueron unívocamente beneficiosos para la eficaz labor de inserción en el movimiento obrero (Camarero, 2011). Si bien el incremento de la orientación confrontacionista ayudó en cierto sentido a esta última, tuvo contrapartidas notables: colocó a los comunistas en posiciones aventureras que llevaron a varias derrotas en huelgas lanzadas por cuenta y orden del partido, sin medir si la oportunidad era adecuada y si la correlación de fuerzas era favorable para tomar estas decisiones; además, los ubicó por fuera de la principal organización gremial del país (la CGT), al constituir una agrupación sectaria y aislada, el Comité de Unidad Sindical Clasista (CUSC).

Por otra parte, el gran viraje de 1935, que condujo a la aplicación de la estrategia del "frente popular" antifascista, produjo otros efectos contraproducentes en el papel de los comunistas en el movimiento obrero, pero de un orden distinto: se fueron supeditando, desde la retórica y desde la práctica, las reivindicaciones de los trabajadores a una política de acuerdo con la burguesía "aliada" y "democrática". Los comunistas, mientras se hacían fuertes en los sindicatos industriales y canalizaban las demandas laborales, en el terreno político, en cambio, propiciaban todo tipo de convenios con expresiones pretendidamente "progresistas" del campo patronal. Hicieron lo imposible para establecer una gran alianza opositora al gobierno conservador junto a la UCR, el PDP y el PS, levantando con ahínco la candidatura de Marcelo T. de Alvear a la presidencia en 1937. Esta línea fue anestesiada en el bienio 1939-1941, cuando perduró el tratado de no agresión nazi-soviético RibbentropMólotov y por ende se estableció la táctica del "neutralismo". Pero desde junio de ese último año, con la invasión alemana a la URSS, el frentepopulismo volvió con vigor y encontró al PC como el más entusiasta impulsor de lo que años después derivó en la Unión Democrática.

Todas estas cuestiones han sido tradicionalmente señaladas en la bibliografia. Pero no se buscó identificar las razones profundas que explicaban estas derivas estratégicas del PC. Ellas remitian a un desvarío programático del partido, originado en la hipoteca teórica, ideológica y política que éste tenía con el estalinismo. En este sentido, no ayudó en mucho identificar la existencia de supuestas "estrategias" propias y objetivas de la clase obrera, en buena medida, intangibles e incomprobables en un plano de análisis histórico-concreto e inciertas desde el punto de vista teórico. Las estrategias que sí pueden evaluarse son las que explícita y materialmente aparecen formuladas en el escenario de 
la lucha de clases, provenientes de las direcciones sindicales y politicas que aparecen en juego. ¿Sobre qué bases programáticas se sostenian las del PC? ¿Cuáles eran los fundamentos del frentepopulismo que cada vez más incómodamente mezclaba clasismo y combatividad en la lucha sindical con tendencias a la conciliación de clases en el terreno político?

Desde fines de la década de 1920 (más exactamente a partir del VIII Congreso, realizado en 1928), el PC radiografió la estructura socioeconómica del país en términos de un capitalismo deformado por el imperialismo, el latifundio y los resabios semifeudales. De alli derivó su caracterización de que el país requería de una revolución "democráticoburguesa, agraria y antiimperialista"; en el futuro indeterminado, sobrevendría el horizonte socialista. Paradójicamente (o no) esta definición se postuló como parte de la política sectaria y ultraizquierdista de "clase contra clase"; aún se concebía que la burguesía nacional cumpliría un papel contrarrevolucionario, por lo cual estaría en manos de la clase obrera y de sus aliados campesinos el destino de aquella revolución. Este planteo etapista se afianzó e incorporó nuevos rasgos con la adopción del llamado al "frente popular" (1935), fundamentado plenamente en el IX Congreso de 1938 y profundizado en el X Congreso de 1941. La paradoja es que el autodenominado "partido de la clase obrera" terminaba definiendo como problema principal del país no al capitalismo, sino al insuficiente desarrollo del mismo. Según su análisis, la industria vernácula había quedado constreñida en límites estrechos y el sector rural estaba sometido a un régimen de explotación ineficiente y caduco, todo distorsionado por la perniciosa influencia del capital monopolista y los terratenientes. En esos marcos, la burguesía nacional aparecía frágil e imposibilitada de asegurar un camino de independencia y progreso, pero dado que presentaba contradicciones con el imperialismo, ocupaba un lugar clave en la interpelación comunista. La contradicción entre la clase obrera y los capitalistas quedaba relegada a un segundo plano y subalternizada en toda la orientación estratégica del partido. Ahora se sostendría que el proletariado poseía aliados naturales en el campo de una fantasmal burguesía nacional desvinculada del capital extranjero y la oligarquía agraria.

A todo ello, el PC agregó una lucha contra el fascismo y por la democracia, sin ningún tipo de especificación del carácter de clase de esos fenómenos, lo cual terminó reforzando un programa reformista y de conciliación con fracciones de la burguesía. En ello, empalmó con el PS. De este modo, hacia comienzos de los años 40, la mayor parte de la izquierda no expresaba una hegemonía politica genuinamente socialista en las masas populares; incluso, convertía en precario su predominio sindical entre los trabajadores. El socialismo alcanzaba sus mayores 
bancadas parlamentarias y confiaba en mantener la lealtad (lo que finalmente no se verificó) entre sus muchos dirigentes en gremios como el de los municipales, empleados de comercio o ferroviarios, mientras el comunismo consolidaba su poderío en el sindicalismo industrial y ganaba espacios dentro de la CGT. Sin embargo, ambos partidos se unificaban en torno a un proyecto aliancista con fuerzas sociales y políticas tradicionales, detrás de un programa republicanista y antifascista de dificil conjugación con las demandas efectivas de una clase obrera en ascenso numérico y movilizacional. ${ }^{6}$

El amplio y difuminado espacio del sindicalismo, que volvía a hacerse del control de la CGT, de la mano de José Domenech y sus ferroviarios, tenía problemas de otra índole. Muchos de sus principales cuadros, con carnet de afiliados al PS, en la práctica estaban emancipados de todo disciplinamiento partidario, lo cual revelaba muy bien las dificultades que siempre acarreó el socialismo de Juan B. Justo para articular la lucha sindical con la política. Así, el tradicional pragmatismo economicista, corporativismo y apoliticismo de estos dirigentes gremiales, los distanció definitivamente de las izquierdas partidarias, pero no para superar las limitaciones de aquellas, sino para montar un proyecto también regresivo, el de consolidarlos como corriente en disponibilidad para aportar base al otro proyecto burgués emergente en 1943-1944, el del peronismo. Es respecto a este asunto donde obras como las de Murmis-Portantiero o Del Campo no pudieron capturar completamente el dilema planteado: estos autores pusieron el énfasis en el proyecto de autonomía sindical que aquellos cuadros gremiales estaban representando en la escena histórica, pero sin sopesar adecuadamente la experiencia de heteronomía política a la que los conducía, es decir, su posterior disolución-derrota en un nuevo movimiento politico policlasista burgués.

\section{¿Derrota autoinfligida o bloqueo populista?}

Diagramemos el proceso que tuvo como resultado la derrota del comunismo y la izquierda partidaria frente a la emergencia del peronismo. Desde los inicios mismos del golpe del 4 de junio de 1943, y especial-

6. Hay que examinar hasta qué límites el PC se alejó de las necesidades de los trabajadores, y si, en especial, en la coyuntura 1941-1943, le dio explícitamente la espalda a las luchas de éstos. Se ha aludido la práctica de "tregua laboral" de los comunistas, con la entrada de la URSS a la guerra y con el acuerdo con los aliados y la "burguesía progresista". No obstante, es necesario abordar con cuidado el tema: fuera del conocido caso del gremio de la carne, donde el PC impulsó esa línea en 1943, escasean las evidencias de "tregua laboral". En verdad, en esos años, los gremios comunistas encabezaron las mayores huelgas en el sector industrial. 
mente desde que Perón impulsó la Secretaría de Trabajo y Previsión, se alertó el peligro que representaba la gravitante presencia del PC en los ámbitos laborales y la necesidad de erradicarlo. Esta propaganda anticomunista tuvo un rédito escaso: es probable que el empresariado encontrara una preocupación mayor en las concesiones laborales que estaba otorgando el propio Perón, un proceso permitido por la favorable coyuntura económica de la época. Lo cierto es que este último se lanzó a una política propia, de aplastamiento de los sectores sindicales ligados al PC. Perón fue enhebrando relaciones con diversas conducciones gremiales, con el fin de articular una nueva estructura afin a sus posiciones. Varios dirigentes laborales, sobre todo provenientes del sindicalismo y/o tránsfugas del PS, fueron tentados por esa convocatoria. Alli donde el PC controlaba la organización gremial, Perón no dudó en alentar la fundación de "sindicatos paralelos", con el objetivo de incrementar su base de apoyo en el movimiento obrero y provocar una competencia a la presencia de ese partido.

Perón y su grupo fueron señalados por el PC como el enemigo principal, en una lectura de la realidad que resultó muy necia, esquemática e incapaz de advertir la compleja trama de realidades y expectativas que comenzaban a tejerse en torno al vínculo entre ese militar y los trabajadores. En buena medida, ello se debía a la estrategia de compromiso con las expresiones de la "burguesía democrática" que el estalinismo venía impulsando con su línea frentepopulista. Se denunció al coronel como el continuador más pérfido del régimen implantado en 1943 y de las dictaduras totalitarias del Eje nazi-fascista. La multiplicación de los sindicatos paralelos, la orientación de otros ya constituidos hacia un acuerdo con el Secretario de Trabajo, la irrupción popular inesperada del 17 de octubre que lo rescató de su detención y ostracismo, la creación del Partido Laborista por parte de la vieja guardia sindical dispuesta a realizar un acuerdo con el restituido líder militar y el triunfo de la candidatura presidencial de este último en febrero de 1946 como expresión de una amplia coalición socio-política sostenida en el apoyo sindical, son algunos de los hitos de un proceso que nos señala el éxito del peronismo en ganar la adhesión de los trabajadores y la derrota del PC por impedir este intento.

En este punto deben explorarse de manera global y comprensiva las razones que permiten explicar el eclipse comunista en el movimiento obrero y la conversión mayoritaria de este último al peronismo. A nuestro entender, la mirada exige atender a dos elementos cruciales e interrelacionados. Uno, el ya analizado de la estrategia frentepopulista del PC, que dilapidó una tradición sindical combativa y clasista, detrás de un proyecto y un programa de colaboración de clases, lo cual acabó desarmando ideológicamente al movimiento obrero y lesionando seria- 
mente su autonomía política. El otro no puede ser sino el que conduzca a apreciar adecuadamente el carácter extraordinario con que irrumpió en la Argentina el fenómeno populista y nacionalista burgués (bajo una cultura "obrerista" y a la vez "antiizquierdista"). La clave para resolver lo que aparece como una anomalía histórica es el desacople entre dos fenómenos contrapuestos: por un lado, el crecimiento rápido y exponencial de la alianza entre un sector mayoritario del gremialismo (celoso en defender la autonomía sindical pero impotente para resistir una tendencia a la heteronomía política) y la elite militar-estatal encabezada por Perón; por el otro, el importante desarrollo que venian experimentando los comunistas en el mundo del trabajo, que era más lento, gradual, incompleto y cada vez más dilapidado por una estrategia politica que potencialmente lo distraía de las reivindicaciones de los trabajadores. Además de comenzar a agotarse parcialmente en su propia dinámica por limitaciones de estrategia política e ir feneciendo de "muerte natural", la influencia del comunismo en el movimiento obrero fue obturada y reprimida por la decisiva acción de un movimiento populista emergente. Hubo una perfecta articulación entre causas endógenas (las características de la orientación partidaria antes descripta) y exógenas (la notable vitalidad de la interpelación y acción del nacional-populismo, con su estatismo redistribucionista). Un modo de comprobar la necesidad de conjugar ambas dimensiones es apelar al estudio comparativo con otros casos latinoamericanos próximos, como los de Chile, Uruguay y Brasil. Estos países en los años 20 y los 30 tuvieron partidos comunistas con un nivel de arraigo en la clase obrera no mayor que en la Argentina, pero que pudieron incrementar o mantener en las décadas siguientes, a pesar de que estuvieron embarcados bajo la misma línea del frente popular que distinguió al PC de Ghioldi y Codovilla. ¿No es acaso sugerente el hecho que en estos países no existió un fenómeno populista y nacionalista burgués de la magnitud, la complejidad y la consistencia que tuvo en la Argentina?

Conducir el análisis en esta dirección implica cuestionar las interpretaciones que tendieron a abordar este proceso histórico de manera unilateral. Los señalamientos sobre el peso que la orientación del frente popular tuvo en el sentido de impedir la hegemonía obrera comunista hacia comienzos de los años 40, convirtiéndose en una suerte de "derrota autoinfligida", han frecuentemente desatendido el significado del "bloqueo populista" antes mencionado. Por otra parte, es bastante obvio que si el PC fue perdiendo sus posiciones en el movimiento obrero desde 1943-1944 no fue por algún tipo de esencialismo "antinacional" o "antipopular", característico de esa organización (y de toda la izquierda socialista y marxista), tal como se sostuvo desde cierto ensayismo (Puiggrós, Ramos y sus continuadores). Tampoco, por un cambio en la 
composición social de los trabajadores, que habría ido erosionando la influencia de los viejos partidos de clase y los habría tornado incapaces de organizar a la "nueva clase obrera", como se desprende de los estudios sociológicos de Germani y otros autores; de hecho, el comunismo fue la corriente que mejor logró expandirse entre el joven proletariado formado como producto del crecimiento industrial de los años treinta.

A manera de epílogo, si ponderamos en su real dimensión el desarrollo que venía experimentando el PC, es posible establecer que la irrupción del peronismo desde 1943-1944 y la adhesión mayoritaria que concitó entre los trabajadores no se presentó ni como la única e inevitable alternativa histórica ni como la consecuencia "lógica" y "natural" de las transformaciones económicas, sociales y políticas acaecidas desde la década de 1930. En todo caso, el peronismo fue la opción que se tornó triunfante en aquellas circunstancias, y la que logró recoger los frutos de un sindicalismo industrial y "moderno" al que tanto habia contribuido a erigir precisamente el PC y otras corrientes de izquierda. En un ejercicio contrafáctico, sobre una Argentina con un 17 de octubre frustrado, es decir, sin un triunfo del peronismo ¿es posible conjeturar que se hubiera asistido a una continuidad o incluso profundización de la presencia comunista en los medios obreros, entre otras razones, por el inevitable aumento cuantitativo de las clases trabajadoras, el acrecentamiento de los problemas provenientes del mundo del trabajo y el peso que tenian las ideologias y tradiciones de izquierda? (Torre, 1999). La pregunta es pertinente si le añadimos como otro factor inevitable de análisis el de la estrategia politica que guiaba al PC, un partido ya completamente ganado por la rigidez monolítica, matrizado por la indigencia teórica-política del estalinismo y sometido a los dictados de la burocracia soviética.

De un modo u otro, fue en la coyuntura 1943-1945 cuando periclitó la que hasta el día de hoy fue la más importante experiencia de inserción de un partido de izquierda en la clase trabajadora argentina. El examen de las razones que explican este proceso de auge y declive siguen siendo uno de los puntos nodales para un programa de estudio sobre la historia del movimiento obrero y la izquierda en la Argentina, en la que en este texto pretendimos brindar algunas hipótesis y conclusiones teóricas y analiticas.

\section{Referencias}

Aguila, Gabriela B. (1991-1992), "Los comunistas y el movimiento obrero en Rosario, 1943-1946", Anuario Escuela de Historia, Facultad de Humanidades y Artes, UNR, segunda época, 14, Rosario.

Anderson, Perry (1984), "La historia de los partidos comunistas", en R. 
Samuel (ed.): Historia popular y teoria socialista, Barcelona: Crítica, pp. 150-165.

Arévalo, Oscar (1983), El Partido Comunista, Buenos Aires: CEAL.

Aricó, José (1979), "Los comunistas en los años treinta", Controversia, 2-3 (suplemento $\mathrm{n}^{\circ} 1$ ), México, diciembre, pp. v-vii.

Camarero, Hernán (2001), "El Partido Comunista argentino en el mundo del trabajo, 1925-1943. Reflexiones historiográficas e hipótesis exploratorias", Ciclos en la historia, la economía y la sociedad, XI, 22, $2^{\circ}$ semestre, pp. 137-155.

- (2005), "La izquierda como objeto historiográfico. Un balance de los estudios sobre el socialismo y el comunismo en la Argentina", Nuevo Topo. Revista de historia y pensamiento crítico, I, 1, septiembre-octubre, pp. 77-99.

- (2007), A la conquista de la clase obrera. Los comunistas y el mundo del trabajo en la Argentina, 1920-1935, Buenos Aires: Siglo XXI Editora Iberoamericana.

- (2008), Comunismo y movimiento obrero en la Argentina, 1914-1943. Tesis doctoral. Facultad de Filosofia y Letras, Universidad de Buenos Aires.

- (2011), "El tercer periodo de la Comintern en versión criolla. Avatares de una orientación combativa y sectaria del Partido Comunista hacia el movimiento obrero argentino", en A Contracorriente. A Journal on Social History and Literature in Latin America, North Carolina State University, Vol. VIII, $\mathrm{N}^{\circ} 3$, primavera, pp. 203-232.

Campione, Daniel (1996), "Los comunistas argentinos. Bases para la reconstrucción de su historia", Periferias. Revista de Ciencias Sociales, I, 1 , segundo semestre, pp. 103-115.

Cernadas, Jorge, Roberto Pittaluga y Horacio Tarcus (1998), "La historiografia sobre el Partido Comunista de la Argentina. Un estado de la cuestión", El Rodaballo. Revista de politica y cultura, IV, 8, otoño-invierno, pp. 30-39.

Ceruso, Diego (2010), Comisiones internas de fábrica. Desde la huelga de la construcción de 1935 hasta el golpe de estado de 1943, Vicente López: PIMSA/Dialektik.

Collinet, Michel (1955), El espiritu del sindicalismo, Buenos Aires: Ediciones Populares Argentina.

Del Campo, Hugo (1983), Sindicalismo y peronismo. Los comienzos de un vinculo perdurable, Buenos Aires: CLACSO.

Di Tella, Torcuato S. (2003), Perón y los sindicatos. El inicio de una relación conflictiva, Buenos Aires: Ariel.

Durruty, Celia (1969), Clase obrera y peronismo, Buenos Aires: Pasado y Presente.

Fava, Athos (1983), Qué es el Partido Comunista, Buenos Aires: Sudamericana.

Fernández de Ullivarri, María (2010), Trabajadores, sindicatos y politica en Tucumán, 1930-1943. Tesis doctoral. Facultad de Filosofia y Letras, Universidad de Buenos Aires. 
Galasso, Norberto (2007), Aportes criticos a la historia de la izquierda argentina. Socialismo, peronismo e izquierda nacional, T. I, Buenos Aires: Nuevos Tiempos.

Germani, Gino (1962), Política y sociedad en una época de transición. De la sociedad tradicional a la sociedad de masas, Buenos Aires: Paidós.

Godio, Julio (1989), El movimiento obrero argentino (1930-1943). Socialismo, comunismo y nacionalismo obrero, Buenos Aires: Legasa.

Gramsci, Antonio (1984), Notas sobre Maquiavelo, sobre politica y sobre el Estado moderno, Buenos Aires: Nueva Visión.

Groppo, Bruno y Bernard Pudal (2000), "Une réalité multiple et controversée”, en M. Dreyfus, B. Groppo, C. Ingerflom y otros (dirs.), Le siècle des communismes, Paris: Les Éditions de l'Atelier/Éditions Ouvrières.

Haupt, Georges (1986), El historiador y el movimiento social, Madrid: Siglo XXI.

Horowitz, Joel (2004), Los sindicatos, el Estado y el surgimiento de Perón, 1930-1946, Buenos Aires: Eduntref.

Iñigo Carrera, Nicolás (2000), La estrategia de la clase obrera, 1936, Buenos Aires: La Rosa Blindada-PIMSA.

Iscaro, Rubens (1958), Origen y desarrollo del movimiento sindical argentino. Buenos Aires: Anteo (luego: Historia del movimiento sindical, Buenos Aires: Fundamentos, 1973).

Korzeniewicz, Roberto P. (1993), "Las vísperas del peronismo. Los conflictos laborales entre 1930 y 1943, Desarrollo Económico. Revista de Ciencias Sociales, XXXIII, 131, octubre-diciembre, pp. 323-354.

Lobato, Mirta Zaida (2001), La vida en las fábricas. Trabajo, protesta y politica en una comunidad obrera, Berisso (1904-1970), Buenos Aires: Prometeo Libros/Entrepasados.

Mastrángelo, Mariana (2011), Rojos en la Córdoba obrera, 1930-1943, Buenos Aires: Imago Mundi.

Matsushita, Hiroshi (1983), Movimiento obrero argentino, 1930-1945. Sus proyecciones en los orígenes del peronismo, Buenos Aires: Siglo veinte.

Murmis, Miguel y Juan Carlos Portantiero (1971), Estudios sobre los origenes del peronismo, Buenos Aires: Siglo XXI.

Partido Comunista, Comisión del Comité Central (1947), Esbozo de Historia del Partido Comunista de la Argentina (Origen y desarrollo del Partido Comunista y del movimiento obrero y popular argentino), Buenos Aires: Anteo.

Paso, Leonardo (1983), Historia de los partidos politicos en la Argentina (1900-1930), Buenos Aires: Directa.

Pastoriza, Elisa (2005), "Ciudad y memoria social: los que construyeron Mar del Plata: militancia obrera y proyectos gremiales comunistas en vísperas del peronismo", en N. Álvarez, C. Rustoyburu y G. Zuppa (comps.), Pasado y presente de la Mar del Plata social, Mar del Plata: FUDEM, pp. 101-122.

Peter, José (1968), Crónicas proletarias, Buenos Aires: Esfera. 
Puiggrós, Rodolfo (1956), Historia crítica de los partidos politicos argentinos, Buenos Aires: Argumentos.

Ramos, Jorge Abelardo (1962), El partido comunista en la politica argentina, Buenos Aires: Coyoacán.

Tamarin, David (1985), The Argentine Labor Movement, 1930-1945. A Study in the Origins of Peronism, Albuquerque: University of New Mexico Press.

Torre, Juan Carlos (1990), La vieja guardia sindical y Perón. Sobre los orígenes del peronismo, Buenos Aires: Sudamericana.

- (1999), "La Argentina sin el peronismo. ¿Qué hubiera ocurrido si hubiese fracasado el 17 de octubre?", en Niall Ferguson (dir.): Historia virtual. ¿Qué hubiera pasado si...?. Madrid: Taurus.

$$
* * *
$$

Resumen: Este artículo aborda el ascenso y el declive del Partido Comunista argentino en el movimiento obrero durante el período de entreguerras. Comienza con un balance historiográfico en torno al tema. Luego, examina cuándo, cómo y por qué el PC echó raíces de manera orgánica en la clase obrera hasta 19431945, explorando, en particular, las condiciones y circunstancias que hicieron posible tanto el proceso de inserción comunista entre los trabajadores como el posterior fenómeno de pérdida de esta influencia, ocurrido con el advenimiento del peronismo al poder. Asimismo, se analiza el aporte del PC al surgimiento de un sindicalismo industrial y de masas, que luego fue extendido y potenciado por el peronismo. Por último, se evalúa el impacto de las diversas estrategias impulsadas por el partido: desde la de "clase contra clase" a la del "frente popular".

Palabras clave: Argentina - Partido Comunista - Movimiento obrero - Frente popular - Peronismo

\begin{abstract}
This article discusses the rise and fall of the Communist Party of Argentina in the labor movement during the interwar period. It begins with a historiographical balance on that issue. Then, it examines when, how and why the PC took root in the working class until 1943-1945, exploring in particular the conditions and circumstances that made possible both the Communists' insertion among workers and the subsequent loss of that influence, which took place with the advent of Peronism to power. It also analyzes the Communists' contribution to the emergence of industrial and mass unionism, which was later extended and enhanced by Peronism. Finally, we evaluate the impact of various strategies adopted by the party: class against class and the popular front.
\end{abstract}

Keywords: Argentina - Communist party - labor movement - Popular front Peronism

Recepción: 28 de junio de 2012 - Aprobación: 14 de julio de 2012 